\title{
Research Trends in Diabetes Applying VOS Viewer: A Scientometric Profile
}

\section{OPEN ACCESS}

Manuscript ID:

ASH-2021-09024283

Volume: 9

Issue: 2

Month: October

Year: 2021

P-ISSN: 2321-788X

E-ISSN: 2582-0397

Received: 02.07.2021

Accepted: 05.09.2021

Published: 01.10.2021

Citation:

Catherin Beula, C., and Chandran Velmurugan.

"Research Trends in Diabetes Applying VOS Viewer: A Scientometric Profile." Shanlax International Journal of Arts, Science and

Humanities, vol. 9, no. 2, 2021, pp. 93-103.

DOI:

https://doi.org/10.34293/ sijash.v9i2.4283

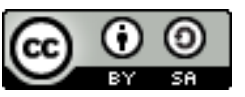

This work is licensed under a Creative Commons Attribution-ShareAlike 4.0 International License

\author{
C. Catherin Beula \\ Librarian, TDMNS College, T. Kallikulam, Tamil Nadu, India \\ https://orcid.org/0000-0002-8320-3115
}

\section{Chandran Velmurugan}

Librarian and Head, Meenakshi Medical College Hospital and Research Institute

(MMCH \& RI), Enathur, Kanchipuram, Tamil Nadu, India

\begin{abstract}
As diabetes is a non-communicable disease, many scientists try to cure it in different ways throughout the globe. Due to the remarkable scientific growth in this area, we focus on evaluating the scholarly publications and their current research trends in diabetes, particularly type 1 diabetes published by Indian scientists using statistical tools and scientometric analysis. A total of 83318 global research productivity and a total number of research publications from India was 2381 with 36, 408 global citations and the Period between 2009 and 2018. Further, the total number of authors (17712) and its average number of authors is 7.44, a total number of 782 core journals and 95228 cited references found during the research period. To evaluate data, various scientometric techniques or indicators were used such as Authorship Pattern (Single vs Multiple), Degree of Collaboration, Relative growth rate (RGR) and Doubling Time (DT) and many more indicators used. This study limits with Indian research output did not include world literature. We try to identify the information in different types of type 1 diabetes between 2009 and 2018. This study will help to find out the core journals for collection management and for promoting diabetes research and developments in future. We chose the core keywords in type 1 diabetes with full records with abstracts, types of manuscripts, cited references using the Web of Science database.
\end{abstract}

Keywords: Diabetes, Type 1 diabetes, Scientometrics, Mapping technology, VOS viewer, Web of Science, h-index, India.

\section{Background}

Scientometrics cope with measuring scientific publications in all subjects to share information. Price (1971) indicated through "Little Science, Big Science" that science is a measurable substance. Consequently, the workforce engaged in science and science could be evaluated by selected statistical methods. Sarala (2005) pointed out that scientometrics covers all quantitative aspects of science, communication in science and science policy. For the present study, scientometric tools have been applied to measure, monitor, and benchmark the performance, inputs, and outcomes of Type 1 Diabetes publications produced by Indian scientists. These indicators help Type 1 Diabetes to formulate policy, setting priorities, and undertake strategic planning, monitoring, and evaluation.

Diabetes is one of the non-communicable diseases and it is called Madhumeh in Hindi. The most celebrated ancient Geek Physician viz "Aretaeus of Cappadocia" coined the term 'Diabetes,' derived from the Greek word 'dia-bangin', the prefix 'dia' denotes 'across or apart', and the word 'bainein' represents 'to walk or stand.' During $250 \mathrm{BC}$, 'diabetes' was used for the first time by the Greed Apollonius of Memphis. Type 1 diabetes is described as the cruellest disease. This diabetes is caused if the insulin level is low or blood sugar or blood glucose level is too high. Type 1 diabetes (T1D) is also known 
as Juvenile or insulin-dependent diabetes. Type 1 diabetes syndrome is connected with genetics and the atmosphere. This disease can direct to loss of function of pancreatic B-cells; it goes through three phases (https://www.trialnet.org). In the first phase, it is seen that there is no signs or symptoms, and blood sugar levels remain healthy, although they affect the $\beta$ cells that produce insulin. In this second phase, we can observe the abnormality caused by the increase in the loss of $\beta$ cells. But, in the final phase, the immune system changes the blood sugar level due to losing a huge number of $\beta$ cells. As a result, the symptoms of Type 1 diabetes (T1D) were found to be visible.

\section{Previous Work}

Velmurugan and Radhakrishnan (2015) conducted to recognise the level of the growth pattern of research articles in Pharmacognosy. They found that the highest number of research output was in 2010 and the least number of articles were in 1989. It was also noted that German Cancer Research Centre ranked first and followed by Brazil and India. Gou et al. (2018) studied metabolomics to discover research trends, wise country publications, prolific authors and journals during the period between 1992 and 2017. A total number of 66721 scientific publications were found in metabolomics with full records and cited references from 1st January 1992 to 16th July 2017. They identified that the most productive 15 countries ranked by the total number of records in metabolomics. They noted that the United States had ranked first with 20414 research articles, followed by China (7761) and Germany (5689). Goa et al. (2017) carried out a study on diabetes mellitus and T Cells during 1997-2016. A total of 1077 research publications with 28109 citations were found using the Web of Science database. The results showed that the prolific country was the United States (48.38\%) of publications and the most productive year was 2011 (7.89\%) while measuring the number of records per year. They investigated that most of the research papers published in the 'Journal of Immunology' and, followed by 'Nature'. Harande (2011) investigated to assess the research growth and mounting the diabetes-related scientific publications in Nigeria. The findings revealed that the publications growth rate was significantly increased from 1986 onwards on diabetes. He also found that there was enormous progress in terms of teaching and research institutes in the country.

\section{Need for the Study}

In recent days research publications have been part and parcel of academic society. Scholarly scientific articles take part in the most important role in the learned society at the global level. It is noteworthy that the publications of research articles, reports, articles in conference proceedings have radically increased gradually in all the fields. Correspondingly, publishing scholarly papers are a part of research in any field such as Medicine, Engineering, Science and Technology, Social Science in many Universities and Colleges in India. Moreover, it is mandatory for the research scholars to publish their research contents in peer-reviewed journals at national and global levels. Conversely, due to the accelerating cost of periodicals and insufficient economic points of libraries and information centres, the selection and subscription of particular journals for a library should be made vigilantly. Library professionals are forced to reduce the number of journal subscriptions. In this circumstance, Scientometric studies have multi-faceted applications on Library and Information Science in analysing the growth of research to framing subscription policies for the future. This study will help LIS professionals to manage collection development as well as for research scholars to publish their research articles.

\section{Objectives}

The study has been intended with the major purposes are given such as:

1. To find out the growth rate of the most productive year/years of the research papers on diabetes type 1 research in the World and India,

2. To identify the most preferred types of publications like journal articles, article review, conference proceedings, etc.,

3. To observe the most productive countries and most preferred journals on type 1 diabetes, and

4. To identify the productive authors, degree of collaboration in the field of type 1 diabetes. 


\section{Hypotheses}

1. The Relative Growth Rate (RGR) demonstrates the decreasing trend and the Doubling Time (DT) reflects an increasing trend in type 1 diabetes research.

2. The Journal articles on type 1diabetes are predominant than other forms of publications.

3. The collaborative research dominates type 1 diabetes during the study period.

\section{Material and Methods}

The data was collected in Diabetes Type 1 research publications from the bibliographic database of two selected versions such as Science Citation Index (SCI), Science Citation Index - Expanded (SCI-E), which are available in the Web of Science maintained by Clarivate Analytics, formerly Thomas Reuters. The study period between 2009 and 2018 has been chosen for downloading the source data. To search the data, Web of Science Core Collection has been selected and keywords such as "(Diabetes Type 1) OR TOPIC: (Type 1 diabetes) OR TOPIC: (Insulin-dependent diabetes) OR TOPIC: (Juvenile onset diabetes) AND TOPIC: (Juvenile diabetes)". The downloaded data contains the documents such as articles, reviews, meeting abstracts, letters, editorial materials, articles in proceedings papers, articles in book chapters, articles in data papers, and review in book chapters, correction and retraction. A total of 83318 global research productivity and a total number of research publications from India was 2381 with 36, 408 global citations and the Period between 2009 and 2018 .

Further, the total number of authors (17712) and its average number of authors is 7.44 , a total number of 782 core journals and 95228 cited references found during the research period. To evaluate data, various scientometric techniques or indicators were used such as Authorship Pattern (Single vs Multiple), Degree of Collaboration, Relative growth rate (RGR) and Doubling Time (DT) and many more indicators used. Moreover, computer free software such as HistCite and VOSviewer has been applied to retrieve and visualise the data and interpretation.

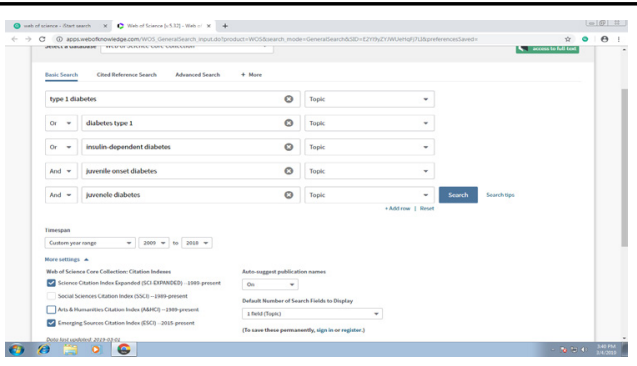

Figure 1: Mapping of Keywords Search on type 1 diabetes

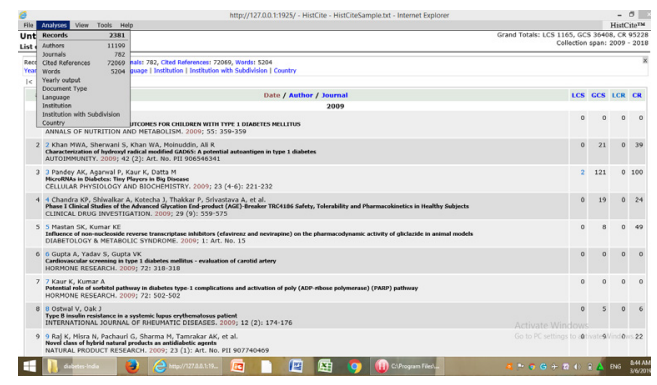

Figure 2: Mapping of HistCite Image of type 1 diabetes during 2009-2018

\section{Bibliometric Indicators used for Analysis}

Citation per paper or article or ACPP is an average citation per paper or articles used by Zhi Lei and Yuh-Shan Ho (2008) to compute the impact of literature output of years, countries, institutes and authors and keywords. The formula of CPP or ACPP is expressed as a total number of citations for a discipline or country or institution divided by a total number of articles. In contrast, the Relative Citation Impact (RCI) technique is applied to evaluate the influence and visibility of a country's research at a global perspective. For this method, the formula is expressed as RCI = Percentage of total citations in a particular year divided by percentage of a total number of publications in a particular year. Therefore, ACPP and RCI have been applied for a consequential comparison of the impact of the scholarly publications for productive countries, fruitful institutions and prolific authors. These two indicators have been extensively used in bibliometrics and scientometric research to normalise the large disparity in published literature among disciplines, countries and institutions to identify the significant relationship of research impact (Dwivedi et al., 2015, 2017). 


\section{Results}

\section{Share of Publications}

Table 1 describes citation per paper and the relative citation impact of Type 1 diabetes in India. The average citation per paper is calculated by the total number of citations divided by the number of articles. The relative citation impact is measured through the percentage of total citations in a particular year divided by the percentage of total publications in a particular year. Based on the records, the massive number of ACPP was 46.93 in 2009, and the smallest number of ACPP was 1.11 in 2018. The growth of ACPP is calculated based on global citations. Accordingly, if the citation level is reduced, its impact will be on the ACPP's. In this investigation, the ACPP shows a fluctuating trend, whereas the relative citation impact shows the highest number of RCI, 3.09 in 2009, whereas the smallest amount of RCI was 0.07 in 2018. The RCI value calculated as 1 is normal, the value greater than 1 is above normal, and the value less than 1 is below normal. Therefore, from table 0.0 , it is identified that the years 2009 and 2012 have above normal RCI with 3.09 and 2.24 respectively and followed by the years 2010, 2011, 2013, and 2014 have normal RCI and years 2015 to 2018 have below normal RCI.

Table 1: Analysis of Growth Rate, Citation per Paper and Relative Citation Impact

\begin{tabular}{|c|c|c|c|c|c|c|c|}
\hline S. No & Total Year & TNP & TNP\% & TGCS* & Total Percent & ACPP* & RCI* \\
\hline 1 & 2009 & 125 & 5.2 & 5866 & 16.11 & 46.93 & 3.09 \\
\hline 2 & 2010 & 125 & 5.2 & 2857 & 7.85 & 22.86 & 1.50 \\
\hline 3 & 2011 & 126 & 5.3 & 3605 & 9.90 & 28.61 & 1.86 \\
\hline 4 & 2012 & 176 & 7.4 & 6044 & 16.60 & 34.34 & 2.24 \\
\hline 5 & 2013 & 176 & 7.4 & 5289 & 14.53 & 30.05 & 1.96 \\
\hline 6 & 2014 & 211 & 8.9 & 3389 & 9.31 & 16.06 & 1.05 \\
\hline 7 & 2015 & 346 & 14.5 & 2710 & 7.44 & 7.83 & 0.51 \\
\hline 8 & 2016 & 354 & 14.9 & 4668 & 12.82 & 13.18 & 0.86 \\
\hline 9 & 2017 & 367 & 15.5 & 1561 & 4.29 & 4.25 & 0.28 \\
\hline 10 & 2018 & 375 & 15.7 & 419 & 1.15 & 1.11 & 0.07 \\
\hline \multicolumn{2}{|c|}{ Total } & 2381 & 100 & 36408 & 100 & & \\
\hline
\end{tabular}

*TNP- Total number of publications, *TGCS- Total Global Citations, ACPP- Average Citation per Paper (ACPP), RCI- Relative Citation Impact

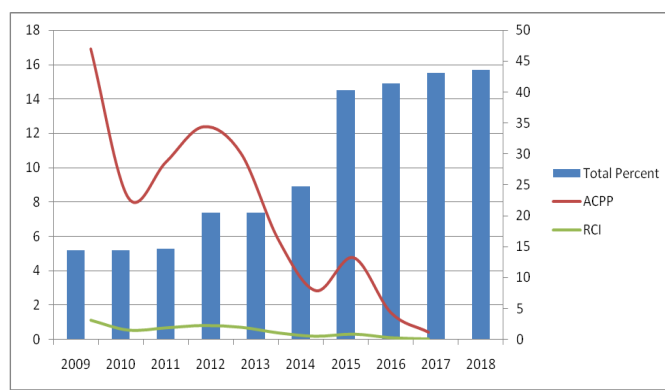

Figure 3. Analysis of Citation per Paper and Relative Citation Impact

\section{Relative Growth Rate (RGR)}

The relative growth rate is an increase in several research papers or pages per unit of time. This scientometric indicator is one of the relevant tools in library and information science which was created by Garg and Pathi in 1999 to evaluate scientific publications in a given field and the same has been applied in type 1 diabetes. The mean relative growth rate () over the specific period of the interval can be evaluated from the below equation.

The relative growth rate formula is expressed as:

1-2R - Log W2-Log W1/T2-T1

Where,

$1-2 \mathrm{R}$ represents the mean relative growth rate over the specific period of interval

Loge W1 - indicates the natural log of the initial number of articles.

Loge W2 - indicates the natural $\log$ of the final number of articles after a specific period of interval. $\mathrm{T} 2-\mathrm{T} 1=$ the unit deviation between the initial time and the final time 
Therefore, the year can be taken as a unit of time = Loge W2 - Loge W1/T2-T1

and the relative growth rate has been computed as:

$2010 \rightarrow=$ Loge $250-$ Loge 125/2010-2009

(aa-1 year-1) determine that the mean relative growth

$=5.52-4.83=0.69$

rate per unit of articles and unit of the year over a specific period of interval.

$2011 \rightarrow=$ Loge $376-$ Loge 126/2011-2010

$=5.52-4.84=0.639$

Table 2: Relative Growth Rate (RGR) AND Doubling Time (DT)

\begin{tabular}{|c|c|c|c|c|c|c|c|c|}
\hline S. No & Year & Records & Percentage \% & Cumulative Records & W1 & W2 & a1-y2 & DT \\
\hline 1 & 2009 & 125 & 5.2 & - & 4.83 & - & - & - \\
\hline 2 & 2010 & 125 & 5.2 & 250 & 4.83 & 5.52 & 0.69 & 1.00 \\
\hline 3 & 2011 & 126 & 5.3 & 376 & 4.84 & 5.93 & 1.09 & 0.636 \\
\hline 4 & 2012 & 176 & 7.4 & 552 & 5.17 & 6.31 & 1.14 & 0.607 \\
\hline 5 & 2013 & 176 & 7.4 & 728 & 5.17 & 6.59 & 1.42 & 0.488 \\
\hline 6 & 2014 & 211 & 8.9 & 939 & 5.35 & 6.84 & 1.49 & 0.465 \\
\hline 7 & 2015 & 346 & 14.5 & 1285 & 5.84 & 7.16 & 1.32 & 0.525 \\
\hline 8 & 2016 & 354 & 14.9 & 1639 & 5.86 & 7.40 & 1.54 & 0.450 \\
\hline 9 & 2017 & 367 & 15.5 & 2006 & 5.90 & 7.60 & 1.70 & 0.407 \\
\hline 10 & 2018 & 375 & 15.7 & 2381 & 5.92 & 7.78 & 1.86 & 0.372 \\
\hline \multicolumn{2}{|c|}{ Total } & $\mathbf{2 3 8 1}$ & $\mathbf{1 0 0}$ & & & & & \\
\hline
\end{tabular}

Above table 2 depicts the RGR and the Doubling Time (DT) for the total records of Type 1 diabetes at the National level. It was found the output of 125 research papers in 2009, and it was increased gradually to 375 in 2018 . The growth rate of publications on type 1 diabetes was from 0.69 in 2010 to 1.86 in 2018 . The year-wise growth shows from 2010 to 2014 is as gradually increased and after that it is seen the fluctuation trend. The highest value indicates in the year 2018 and the lowest value represents 2010. It is also measured the average relative growth rate of scholarly articles on Type 1 diabetes was 1.361 .

\section{The Doubling Time (DT)}

The Doubling Time (DT) for Type 1 diabetes scientific publications is also measured nationally. It finds that the range was from 1.00 in 2010 to 0.372 in 2018 , and its average value of doubling time is 0.544 and shows the declining trend. The results reflect that the relative growth rate has seen an increasing trend in literature output while the doubling time has also decreased in Type 1 diabetes research. Thus, the hypothesis, "The Relative Growth Rate (RGR), shows the increasing trend, and the Doubling Time (DT) illustrates a decreasing trend in Type 1 diabetes research" is proved significantly.

\section{Medium of Scholarly Publications}

Medium of scholarly Publications on type 1 diabetes has been calculated and found a total number of 11 items of manuscripts such as articles, reviews, meeting abstracts, letters, editorial materials, articles in proceedings papers, articles in book chapters, articles in data papers, and review in book chapters, correction and retraction. Out of 2381 publications, a huge number of 2057 publications were articles with 30213 global citations and its h-index is 64 . Reviews had in the second position among 11 items with 210 records along with 5154 citations and its h-index is 32 and followed by meeting abstracts had 60 papers with $1 \mathrm{~h}$-index. It is noted that the below 10 number of manuscripts were 6-11. The results show that researchers have more in publishing papers on original articles and reviews. Hypothesis two indicates that "The Journal articles of type 1diabetes are predominant than other forms of publications" is proved. 
Table 3: Medium of Scholarly Publications

\begin{tabular}{|c|c|c|c|c|c|c|}
\hline S. No & Medium Type & TNP & TNP\% & TGCS & *CPP & h-index \\
\hline 1 & Articles & 2057 & 86.4 & 30213 & 14.69 & 64 \\
\hline 2 & Reviews & 210 & 8.8 & 5154 & 24.54 & 32 \\
\hline 3 & Meeting Abstracts & 60 & 2.5 & 1 & 0.02 & 1 \\
\hline 4 & Letters & 17 & 0.7 & 16 & 0.94 & 2 \\
\hline 5 & Editorial Materials & 16 & 0.7 & 81 & 5.06 & 5 \\
\hline 6 & Article; Proceedings Papers & 8 & 0.3 & 865 & 108.13 & 4 \\
\hline 7 & Article; Book Chapters & 6 & 0.3 & 55 & 9.17 & 4 \\
\hline 8 & Article; Data Papers & 3 & 0.1 & 7 & 2.33 & 2 \\
\hline 9 & Review; Book Chapters & 2 & 0.1 & 11 & 5.50 & 1 \\
\hline 10 & Correction & 1 & 0.0 & 0 & 0.00 & 0 \\
\hline 11 & Retraction & 1 & 0.0 & 5 & 5.00 & 1 \\
\hline & Total & 2381 & 100 & 36408 & & \\
\hline
\end{tabular}

*CPP- Citation per paper

\section{Collaborative research by Institution (Top 10)}

Type 1 diabetes of Indian scientists collaborated with 4657 institutions involved in this research and out of which top 10 institutions has been chosen with more than thirty records. In this context, "All India Inst Medical Science" had ranked first with 113 records and 3870 global citations and its average citation per paper is 34.25 and its h-index is 24 . The next productive institution is "Madras Diabetic Research Foundation" from Chennai with 92 papers. Its h-index is 23 and followed by "Postgrad Inst Medical Education \& Research" from Chandigarh with 2100 citations through 59 publications and had occupied the third rank among them.

Table 4: Collaborative Research by Institution (Top 10)

\begin{tabular}{|l|l|c|c|c|c|}
\hline \multicolumn{1}{|c|}{ Name of the Institution } & \multicolumn{1}{|c|}{ Location } & TNP & TNC & ACPP* & H-Index \\
\hline All India Inst Medical Science & New Delhi & 113 & 3870 & 34.25 & 24 \\
\hline Madras Diabetic Research Foundation & Chennai & 92 & 4123 & 44.82 & 23 \\
\hline Postgrad Inst Med Educ \& Research & Chandrarh & 59 & 2100 & 35.59 & 17 \\
\hline Manipal University & Manipal & 47 & 327 & 6.96 & 10 \\
\hline CSIR & Delhi & 45 & 620 & 13.78 & 15 \\
\hline Dr Mohans Diabet Special Center & Tamilnadu & 35 & 1978 & 56.51 & 16 \\
\hline Banaras Hindu University & Utter Pradesh & 33 & 2566 & 77.76 & 11 \\
\hline Christian Medical College \& Hospital & Chennai & 33 & 2640 & 80.00 & 12 \\
\hline Govt Medical College & Chennai & 32 & 127 & 3.97 & 5 \\
\hline Novo Nordisk AS & Denmark & 32 & 1988 & 62.13 & 15 \\
\hline
\end{tabular}

*ACPP- Average citation per paper

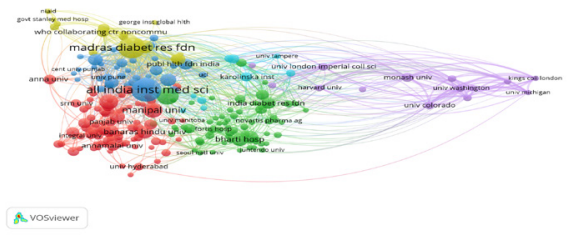

Figure 4: Mapping of Productive Institutions

\section{Collaborative Countries Productivity}

Countries collaboration is one of the effective indicators in scientometrics for evaluation. Here, we have found 114 countries collaborating, including India. It is found that 113 countries collaborated with India to share their views and research output. In this context, United States had collaborated very closely and 343 articles were published with 15519 
global citations. The United Kingdom had placed second with 154 research output along with 11073 global citations. The third productive country is China, with 78 literature and its global citations are 9087. It is noted from the study of Velmurugan and
Ramasamy (2021) through Nephrology Publications and found the United States had got strength with 869 articles and followed by Italy had 217 papers as it strengthens the research in India.

Table 5: Country-wise Distribution (Top 10)

\begin{tabular}{|c|l|c|c|c|c|}
\hline S. No & \multicolumn{1}{|c|}{ Country } & Records & Percent & TLCS & TGCS \\
\hline 1 & India & 2377 & 54.25 & 1159 & 36316 \\
\hline 2 & USA & 343 & 7.71 & 286 & 15519 \\
\hline 3 & UK & 154 & 3.45 & 153 & 11073 \\
\hline 4 & Peoples R China & 78 & 1.76 & 144 & 9087 \\
\hline 5 & Australia & 71 & 1.56 & 71 & 6795 \\
\hline 6 & Canada & 64 & 1.41 & 51 & 6825 \\
\hline 7 & Germany & 56 & 1.23 & 64 & 6838 \\
\hline 8 & Saudi Arabia & 54 & 1.22 & 22 & 2882 \\
\hline 9 & Denmark & 53 & 1.21 & 59 & 6124 \\
\hline 10 & Italy & 51 & 1.14 & 54 & 7761 \\
\hline
\end{tabular}

Moreover, Germany (56, 1.23\%), Saudi Arabia $(54,1.22 \%)$, Denmark $(53,1.21 \%)$ and Italy $(51$, $1.14 \%$ ) had below 60 publications among the top ten countries in type 1 diabetes literature. It seems to us that there is less involvement and interest in publishing work during the study period.

\section{Figure 5: Mapping of Productive Countries}

\section{Most Productive Authors (Top 10)}

Authors play a vital role in any research and publishing research papers is essential. For this research, the author's contribution in the field of type 1 diabetes has been measured. Here, 11199 authors participated and produced research articles on type 1 diabetes in the Indian scenario. Out of which, top prolific authors have been chosen for current analysis and found that the author "Mohan, V" has received 3629 citations with 122 research output and had placed the first and followed by "Anjana RM" had produced 55 research papers with 726 citations and ranked the second place. Tandon $\mathrm{N}$ occupied the third rank with 51 articles and the total citations were 2098.

Table 6: Most productive authors (top 10)

\begin{tabular}{|c|l|c|c|c|}
\hline S. No & \multicolumn{1}{|c|}{ Author } & Records & TLCS & TGCS \\
\hline 1 & Mohan V & 122 & 181 & 3629 \\
\hline 2 & Anjana RM & 55 & 80 & 726 \\
\hline 3 & Tandon N & 51 & 60 & 2098 \\
\hline 4 & Bhansali A & 48 & 57 & 851 \\
\hline 5 & Ghosh S & 45 & 54 & 588 \\
\hline 6 & Kalra S & 44 & 16 & 384 \\
\hline 7 & Kumar A & 43 & 22 & 694 \\
\hline 8 & Ramachandran A & 35 & 61 & 2357 \\
\hline 9 & Kumar S & 33 & 8 & 258 \\
\hline 10 & Gupta A & 31 & 11 & 296 \\
\hline
\end{tabular}




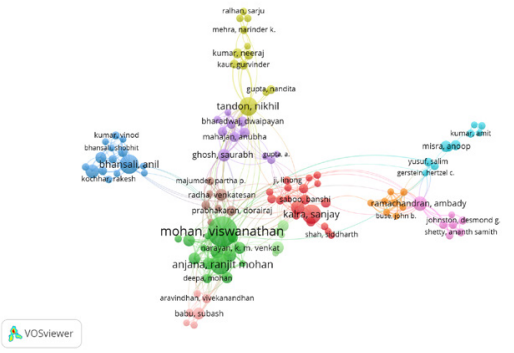

Figure 6: Mapping of Productive Authors

\section{Degree of Collaboration and Collaborative Index}

Collaborative research is one of the essential factors in the field of scientometrics in any subject. Collaboration occurs when two or more researchers or scientists work together on a particular project and contribute endeavours both physically and intellectually. In this context, some collaborative research work has already been carried out by the author on Library Herald by Velmurugan and Radhakrishnan (2015), Biotechnology (2015), Information Literacy (2015), Engineering Journal (2015), Journal of Intellectual Property rights by Velmurugan (2013, 2014), Supply Chain Management (2015), Annals of Library and Information Studies by Velmurugan (2013) Indian Journal of Pure and Applied Physics and Technical Review-Journal by Velmurugan (2014).

To know the strength of collaborative research work in this study, we have chosen two scientometric indicators such as degree of collaboration (DC) suggested by Subramaniam, K (1983) and collaborative index (CI), stated by Lawani in 1980 .

Table 7: Degree of Collaboration

\begin{tabular}{|c|c|c|c|c|c|c|}
\hline Years & TP & TA & TSA & TMA & DC & CI \\
\hline 2009 & 125 & 725 & 2 & 723 & 0.9972 & 5.8 \\
\hline 2010 & 125 & 727 & 4 & 723 & 0.9944 & 5.82 \\
\hline 2011 & 126 & 941 & 2 & 939 & 0.9978 & 7.47 \\
\hline 2012 & 176 & 1043 & 3 & 1040 & 0.9971 & 5.93 \\
\hline 2013 & 176 & 2010 & 4 & 2006 & 0.9980 & 11.42 \\
\hline 2014 & 211 & 1206 & 7 & 1199 & 0.9941 & 5.72 \\
\hline 2015 & 346 & 1871 & 11 & 1860 & 0.9941 & 5.41 \\
\hline 2016 & 354 & 3626 & 13 & 3613 & 0.9964 & 10.24 \\
\hline 2017 & 367 & 3152 & 6 & 3146 & 0.9980 & 8.58 \\
\hline 2018 & 125 & 2411 & 5 & 2406 & 0.9979 & 19.28 \\
\hline Total & 2381 & 17712 & 57 & 17655 & 0.9967 & 7.44 \\
\hline \multicolumn{2}{|c|}{ Percentage (\%) } & 100 & 0.32 & 99.67 & & \\
\hline
\end{tabular}

TP- Total No of Papers, TA- Total No of Authors, TSA- Total No of Single Authors,

TMA- Total No of Multi-Authors

Degree of Collaboration (DC) was suggested by Subramaniam $(\mathrm{K})$ has been applied as given below.

\begin{tabular}{|l|l|l|}
\hline $\begin{array}{l}\text { The formula is expressed as; } \\
\text { C= Degree of Collaboration } \\
\text { Nm = Number of multiple authors }\end{array}$ & $\mathrm{C}=$ & $\mathbf{C}=\frac{\mathbf{N}_{\mathbf{m}}}{\mathbf{N}_{\mathbf{m}}+\mathbf{N}_{\mathbf{s}}}$ \\
Ns = Number of single authors & & \\
\hline & $\mathrm{C}=$ & $\begin{array}{l}18032 \\
17655+57=17712\end{array}$ \\
\hline In the present study, the value of C is & $\mathrm{C}=$ & 0.9967 \\
\hline
\end{tabular}

The productive authors are presented in the the range of the degree of collaboration is from above table 7, year-wise to determine the degree 0.9941 to 0.9980 . It is also found that the average of collaboration. It is found from the table that degree of collaboration is 0.9967 in Type 1 diabetes 
publications during the study period. This analysis brings out the frequency of teamwork that shows the highly collaborative trends in this research. Thus, hypothesis three illustrates that "The collaborative research dominates in diabetes type 1during study period," is proved and accepted.

\section{Identification of Preferred Journals}

As we know well aware that the Journal is the backbone of research publications and it is the right mode of communication for information at the global level. In this context, only the top ten journals are represented in the above table. It is noted that JEMDS had placed first with 495 research publications. "International Journal of Diabetes in Developing Countries" is another productive journal that published 77 records with 231 citations and its h-index is 24. The third rank goes to "Journal of Clinical and Diagnostic Research", with 64 record counts and 115 global citations, 115 and its h-index is 35 .

Table 8: Preferred Journals in Type 1 Diabetes for Publications

\begin{tabular}{|c|l|c|c|c|c|}
\hline S.No & \multicolumn{1}{|c|}{ Journal } & Records & Citations & Country & h-index \\
\hline 1 & $\begin{array}{l}\text { Journal of Evolution of Medical and Dental } \\
\text { Sciences }\end{array}$ & 101 & 10 & India & 24 \\
\hline 2 & $\begin{array}{l}\text { International Journal of Diabetes in Developing } \\
\text { Countries }\end{array}$ & 77 & 231 & India & 35 \\
\hline 3 & Journal of Clinical and Diagnostic Research & 64 & 115 & India & 300 \\
\hline 4 & Plos One & 61 & 1264 & USA & 107 \\
\hline 5 & Diabetes Research and Clinical Practice & 47 & 731 & Ireland & 84 \\
\hline 6 & Diabetes Technology \& Therapeutics & 41 & 488 & USA & 81 \\
\hline 7 & Indian Journal of Medical Research & 33 & 281 & India & 29 \\
\hline 8 & $\begin{array}{l}\text { Diabetes \& Metabolic Syndrome-Clinical } \\
\text { Research \& Reviews }\end{array}$ & 29 & 85 & Netherlands & 82 \\
\hline 9 & Diabetes Obesity \& Metabolism & 28 & 878 & UK & 121 \\
\hline 10 & Journal of Diabetes and its Complications & 28 & 390 & Netherlands & 82 \\
\hline
\end{tabular}

But, analysing using citations and h-index, "PLOS One" from the United States ranked the first with 1264 citations through 61 literature output and its h-index is 300, and followed by "Diabetes Obesity \& Metabolism" from the United Kingdom had ranked with 878 citations through 28 publications and its h-index is 121 . The third predominant journal was "Diabetes Research and Clinical Practice" from Ireland with 731 citations and its h-index is 107.

\section{Conclusion}

Publication analysis is one of the metric studies that is very popular in Library and Information Science research. In this research, type 1 diabetes publications have been chosen for analysis to identify the level of growth and research trends in this area. Therefore, a total number of 83318 global research productivity and a total number of research publications from India was 2381 with 36 ,
408 global citations and the Period between 2009 and 2018. The findings of the study focused on various dimensions and the results reveal that it was measured the average citation per paper and found the massive number of ACPP was 46.93 in 2009, and the smallest number of ACPP was 1.11 in 2018. The ACPP shows a fluctuating trend, whereas the relative citation impact shows the highest number of RCI, a 3.09 in 2009, whereas the smallest amount of RCI is 0.07 in 2018. Relative growth rate and doubling time was evaluated and the results reflect that the relative growth rate has seen an increasing trend while the doubling time has shown a decreasing trend in Type 1 diabetes research. Out of 2381 publications, a huge number of 2057 publications were articles with 30213 global citations and its h-index is 64. It was identified the "All India Inst Medical Science" had ranked first among the top ten institutions with 113 research output and 3870 global citations and its average 
citation per paper is 34.25 and its h-index is 24 . It shows that the United States had collaborated with India very closely and 343 articles were published with 15519 global citations. It was examined the author productivity and found "Mohan, V" received 3629 citations with 122 research output and had placed the first. It was examined the range of the degree of collaboration is from 0.9941 to 0.9980 . It is also found that the average degree of collaboration is 0.9967 in Type 1 diabetes publications. Journal of Evolution of Medical and Dental Sciences (JEMDS) had placed the first in terms of research publications (495). But, counting through citations and h-index, "PLOS One" from the United States ranked the first with 1264 citations through 61 literature output and its h-index is 300 during the period of study.

\section{References}

Dwivedi, Sandhya, et al. "Scientometric Profile of Global Male Breast Cancer Research." Current Science, vol. 112, no. 9, 2017.

Dwivedi, S., et al. "Scientometric Profile of Organic Chemistry Research in India during 20042013." Current Science, vol. 109, no. 5, 2015.

"Diabetes Type 1." Medline Plus, https:// medlineplus.gov/diabetestype1.html

"Diabetes." National Institute of Diabetes and Digestive and Kidney Diseases, https://www. niddk.nih.gov/health-information/diabetes/

de Price, Derek J. Solla. "Some Remarks on Elitism in Information and the Invisible College Phenomenon in Science." Journal of American Society for Information Science, vol. 22, no. 2, 1971, pp. 74-75.

Garg, K.C., and P. Padhi. "Scientometrics of Laser Research Literature as Viewed through the Journal of Current Laser Abstracts." Scientometrics, vol. 45, 1999, pp. 251-268.

Gao, Ye, et al. "Publication Trends of Research on Diabetes Mellitus and T Cells (1997-2016): A 20-Year Bibliometric Study." PLoS One, 2017.

Guo, W., et al. "Deciphering Hepatocellular Carcinoma through Metabolomics: From Biomarker Discovery to Therapy Evaluation." Cancer Management and Research, vol. 10, 2018, pp. 715-734.
Harande, Y.I. "Exploring the Literature of Diabetes in Nigeria: A Bibliometrics Study." African Journal of Diabetes Medicine, vol. 19, no. 2, 2011.

Lawani, S.M. "Bibliometrics: Its Theoretical Foundations, Methods and Applications." LIBRI, vol. 31, no. 4, 1980, pp. 294-315.

Sarala, K.R. "Scientific Productivity of Agricultural Scientists: A Scientometric Study." Library and Information Studies in the Digital Age, edited by G. Devarajan, Ess Ess Publication, 2005.

Subramaian, K. "Bibliometric Studies of Research Collaboration: A Review." Journal of Information Science, vol. 6, no. 1, 1983, pp. 33-38.

“Type 1 Diabetes.” WenMD, https://www.webmd. com/diabetes/type-1-diabetes

“Type 1 Diabetes.” Wikipedia, https://en.wikipedia. org/wiki/Diabetes_mellitus_type_1

Velmurugan, Chandran, and Natarajan Radhakrishnan. "A Scientometric Analysis of Research Papers Published on Pharmacognosy as reflected in the Web of Science." Advances in Pharmacognosy and Phytomedicine, vol. 1, no. 1, 2015, pp. 27-40.

Velmurugan, C., and N. Radhakrishnan. "Research Analysis by Means of Scientometric Techniques on Biotechnology." International Journal of Multidisciplinary Consortium, vol. 2, no. 1, 2015, pp. 256-265.

Velmurugan, C., and N. Radhakrishnan. "Journal of Information Literacy: A Scientometric Profile." Journal of Information Sciences and Application, vol. 3, no. 1, 2015.

Velmurugan, C., and Natarajan Radhakrishnan. "Quantitative Analysis of Scientific Publications Output on Engineering Journal: A Scientometric Study." Journal of Information Sciences and Application, vol. 3, no. 1, 2015, pp. 19-30.

Velmurugan, C., and N. Radhakrishnan. "Literature Output of Supply Chain Management: A Scientometric Approach." Journal of Organizational Behaviour, vol. 3, no. 2, 2015, pp. 31-44. 
Velmurugan, Chandran, and Natarajan Radhakrishnan. "Authorship Trends and Collaborative Research Work on Library Herald: A Scientometric Analysis." Information Science and Digital Libraries, edited by Somvir, International Research Publication House, 2015.

Velmurugan, Chandran. "Research Trends in Journal of Intellectual Property Rights (JIPR): A Bibliometric Study." Library Philosophy and Practice, 2013.

Velmurugan, C. "Scientometric Analysis: Annals of Library and Information Studies Publications Output during 2007-2012." International Journal of Library and Information Studies, vol. 3, no. 3, 2013, pp. 58-65.

Velmurugan, C. "Bibliometric Analysis with Special Reference to Authorship Pattern and Collaborative Research Output of Annals of Library and Information Studies for the Year 2007-2012." International Journal of Digital Library Services, vol. 3, no. 3, 2013,pp. 13-
21.

Velmurugan, C. "Research Trends in Indian Journal of Pure and Applied Physics (IJPAP) for the Year 2009-2012." Asian Review of Social Sciences, vol. 3, no. 1, 2014, pp. 24-28.

Velmurugan, C., and N. Radhakrishnan. "Publication Research Trends on Technical Review Journal: A Scientometric Study." International Journal of Digital Library Services, vol. 4, no. 3, 2014, pp. 45-55.

Velmurugan, Chandran, and G. Ramasamy. "Nephrology Publications of Bibliographic Coupling and Co-authorship Network using VOS viewer: A Scientometric Profile." Library Philosophy and Practice, 2021.

"What is Juvenile Diabetes?" Dexcom, https://www. dexcom.com/faq/what-juvenile-diabetes

"What to Know About Type 1 Diabetes." Medical News Today, https://www.medicalnewstoday. com/articles/323729.php

\section{Author Details \\ Dr. C. Catherin Beula, Librarian, TDMNS College, T. Kallikulam, Tamil Nadu, India. \\ EmailID: beulah.catherin@gmail.com.}

Dr. Chandran Velmurugan, Librarian and Head, Meenakshi Medical College Hospital and Research Institute, (MMCH \& RI), Enathur, Kanchipuram, Tamil Nadu, India, Email ID: murugan73@gmail.com. 